conferência 



\title{
A psicanálise na era trans
}

\author{
Antonio Quinet
}

\begin{abstract}
Resumo
O que responde o psicanalista às questões suscitadas em nossa era trans? Era de transformações cada vez mais rápidas e radicais, políticas, culturais, científicas e também em relação aos sexos e aos corpos. Trans - é bom lembrar - é o prefixo que designa ir para além, atravessar. Estamos na era das ultrapassagens, para bem e para o mal. Era de ir para além dos preconceitos, dos conceitos de família, do sexo, do gênero, da orientação sexual - e isso com consequências subjetivas, éticas, políticas e clínicas. Era também de discursos para além da civilização, como as manifestações de ódio, racismo e segregação em geral, que não têm mais pudor nem barreiras para se manifestar no privado e no público, nas redes sociais e nas ruas. E, por conseguinte, atos terroristas, assassinatos racistas e crimes LGBTfóbicos. Em relação ao sujeito sexuado, o que a psicanálise, com seus conceitos, matemas e sua clínica do real do sexo, tem a contribuir e a se repensar hoje para que estejamos à altura da subjetividade de nossa época? É para isso que estamos aqui, para avançarmos, com Freud e Lacan, na construção do saber psicanalítico, sempre aberto ao singular e às novas manifestações do sujeito do desejo.
\end{abstract}

\section{Palavras-chave:}

Sexuação; Gênero; Trans; Orientação sexual; Tirésias.

\section{Psychoanalysis in the trans age}

\begin{abstract}
What does the psychoanalyst answer to the questions raised in our trans-age? Age of increasingly fast and radical changes, politically, culturally, scientifically and also when it comes to the sexes and bodies. Trans - please note - is the prefix that designates going beyond, crossing. We are in the age of overtaking, for good and evil. Age of going beyond prejudices, concepts of family, sex, gender, sexual orientation - and this with subjective, ethical, political and clinical consequences. Also, age of discourses beyond civilization, such as manifestations of hatred, racism and segregation in general, which no longer show modesty or barriers to manifest publically or privately, in social networks and on the streets. And, therefore, terrorist acts, racist murders and LGBT phobic crimes. The pres-
\end{abstract}


ent work discusses what psychoanalysis, with its concepts, mathemes and its clinical of the sex real, has to contribute and rethink today so that we can live up to the subjectivity of our time. It intends to advance, with Freud and Lacan, in the construction of psychoanalytic knowledge, always open to the singular and to the new manifestations of the subject of desire.

\title{
Keywords:
}

Sexuation; Gender; Trans; Sexual orientation; Tiresia.

\section{El psicoanálisis en la era trans}

\begin{abstract}
Resumen
¿Qué responde el psicoanalista a las cuestiones planteadas en nuestra era trans? Era de transformaciones cada vez más rápidas y radicales, políticas, culturales, científicas y también en relación a los sexos y a los cuerpos. Trans - es bueno recordarlo - es el prefijo que designa ir más allá, atravesar. Estamos en la era de las superaciones, positiva y negativamente. Era de ir más allá de los prejuicios, de los conceptos de familia, sexo, género, orientación sexual, y eso tiene consecuencias subjetivas, éticas, políticas y clínicas. Era también de discursos más allá de la civilización, como las manifestaciones de odio, racismo y segregación en general, que no tienen más pudor ni barreras para manifestarse en lo privado y en lo público, en las redes sociales y en las calles. Y, por consiguiente, actos terroristas, asesinatos racistas y crímenes LGBTfóbicos. Este trabajo discute lo que el psicoanálisis, con sus conceptos, matemas y su clínica de lo real del sexo, tiene a contribuir y a repensar hoy para que estemos a la altura de la subjetividad de nuestra época. Pretende avanzar, con Freud y Lacan, en la construcción del saber psicoanalítico, siempre abierto a lo singular y a las nuevas manifestaciones del sujeto del deseo.
\end{abstract}

\section{Palabras clave:}

Sexuación; Género; Trans; Orientación sexual; Tirésias.

\section{La psychanalyse à l'ère trans}

\section{Résumé}

Que répond le psychanalyste face aux questions soulevées dans notre ère trans - moment de transformations de plus en plus rapides et radicales - au niveau politique, culturel, scientifique et aussi par rapport aux sexes et aux corps? Trans, rappelez-vous, c'est un préfixe qui désigne "aller au-delà", "traverser". Nous sommes à l'âge des dépassements — pour le bien et pour le mal —, d'aller au-delà des pré- 
jugés, des concepts de famille, sexe, genre, d'orientation sexuelle, et cela implique des conséquences subjectives, éthiques, politiques et cliniques. C'est l'ère aussi des discours au-delà de la civilisation, tels que les manifestations de haine, de racisme et de ségrégation en général, qui n'ont plus de pudeur à manifester, soit en privé ou en public, soit dans les réseaux sociaux et dans la rue. Par conséquent, les actes terroristes, les meurtres racistes et les crimes ayant pour cible la population LGBT abondent. Ce travail discute ce que la psychanalyse, avec ses concepts, mathèmes et sa clinique du réel du sexe, a à contribuer aujourd'hui afin que nous puissions vivre à la hauteur de la subjectivité de notre temps. Cet article veut avancer, avec Freud et Lacan, dans la construction du savoir psychanalytique, toujours ouvert à ce qui est singulier et aux nouvelles manifestations du sujet du désir.

\section{Mots-clés:}

Sexuation; Genre; Trans; Orientation sexuelle; Tirésias.

\section{Com Freud}

Freud, em 1920, afirma que "quanto à essência do que, no sentido convencional ou no sentido biológico nomeia-se de 'masculino' e 'feminino', a psicanálise não pode elucidá-la" (Freud, 1920/1976, p. 211). Eis Freud colocando em questão a possibilidade de elucidação de uma suposta essência da masculinidade ou da feminilidade.

Nem biológico que é o sexo (macho ou fêmea), nem o convencional que é o gênero (homem ou mulher) servem para definir masculino e feminino.

A psicanálise não é essencialista, e não é uma ontologia. Ela não define o ser. Para a psicanálise o ser se furta, e lá onde ele poderia comparecer, surge o semblante de ser, que Lacan localiza com o nome de objeto $a$ - produto da caça do real pelos significantes. No que se refere aos gêneros, formações culturais convencionais do masculino e do feminino, não se trata de ser, mas de parecer. Não existe nenhum ser masculino ou ser feminino. A psicanálise tampouco é uma ontologia de gêneros. No texto sobre a feminilidade, Freud (1932/1976) nos aponta para uma ética a esse respeito: não sabemos o que é ser uma mulher, podemos tão somente dizer, por meio de uma análise, como alguém se tornou mulher. Mas não abre mão da diferença sexual.

O que a psicanálise faz com esses conceitos de masculino e feminino que vêm da cultura e da biologia? Freud responde: ela toma esses dois conceitos por conta própria e os coloca na base de seus trabalhos, ou seja, a psicanálise não os toma sem questionamentos; ela os faz trabalhar a partir de seus próprios conceitos. $\mathrm{O}$ trabalho do Inconsciente contesta as convenções recebidas, assim como a biologia, é o que constatamos claramente no divã - o sujeito do Inconsciente não é uma marionete da cultura na qual está inserido, nem um escravo de sua biologia. 
Pelo contrário! Tanto a cultura quanto o corpo biológico passam pelo filtro do Inconsciente e pelo desejo do Outro. O sujeito sexuado se aliena aos significantes do desejo do Outro, que não é exatamente a cultura, e, sim, a cultura do desejo dos pais, os ditos parentais que interpretam os modelos culturais do que se convencionou chamar de masculino e feminino. Mas o sujeito não é só um alienado ao Outro, ele é separado do Outro. Assim, construirá, a seu modo, os semblantes homem ou mulher.

No texto sobre o caso da jovem homossexual, Freud (1920/1976) aponta que, ao se tentar levar os conceitos de masculino e feminino a princípios mais originários, a masculinidade se volatiliza em atividade e a feminilidade em passividade, $\mathrm{o}$ que é, diz ele, muito pouco. Vemos a insatisfação de Freud com sua própria teoria em reduzir o masculino ao ativo e o feminino ao passivo. A conceber o objeto em sua função de causalidade, Lacan retifica essa dualidade, afirmando que o objeto é que é ativo e o sujeito subvertido. E, no entanto, em suas fórmulas da sexuação ele situa o sujeito desejante do lado dito Homem, e o objeto do lado dito Mulher. Lacan, antes de tudo, um freudiano.

Lacan elaborou as fórmulas da sexuação sobre uma premissa extraída do dizer de Freud: não há relação sexual que possa ser escrita.

Nos primórdios da psicanálise, na correspondência com Fliess, Freud já apontava a inexistência da relação sexual como base da neurose: o trauma é o furo entre os seres. O trauma sexual detectado por Freud é relido por Lacan como descompasso do sexo, que ele chama de inexistência da relação sexual. Esse furo na relação entre dois seres sexuados é propriamente falado o traumatismo já detectado por Freud como inadequação entre o desejo e o gozo, quando do mítico primeiro encontro com o real do sexo: indiferença ou nojo na histeria, e excesso e autorrecriminação na neurose obsessiva. Encontro sim, mas relações, não. No sexo: só ralação.

O que vem suprir, no nível da sexualidade, essa ausência? Lacan nos diz que, do lado do homem, é o objeto a que vem no lugar do parceiro de falta, e, do lado dela, da mulher, o que vem em suplência à relação sexual é o significante fálico - aí se encontra o parceiro sexual. Mas há também outro parceiro que pode aparecer sob a face oculta e enigmática de algo para além do Falo - algo misterioso, da ordem do Trans - lá onde deposita o gozo Outro (Lacan, 1975). A não-toda vai para além do fálico, é trans-sexual, trans-fálico.

\section{Os mitos das posições sexuadas}

Há dois mitos que Lacan propõe em O aturdito (1972/2003) para se referir aos dois lados das fórmulas de sexuação, ou, como ele denomina, as duas "metades do sujeito". O mito de Édipo, do lado do todo fálico, e o mito de Tirésias, do lado do não-todo fálico. Do lado dito homem, as fórmulas do Universal e do Um respondem na lógica ao mito de Totem e Tabu, sucedâneo inventado por Freud do mito 
de Édipo e do tabu do incesto. O Universal de "todos submetidos à castração" se conjuga como o Um-da-exceção-que-diz-não à função fálica, ou seja, que diz não à castração. Desse lado, na parte debaixo, encontramos o sujeito desejante, cuja estrutura Freud detectou justamente no mito de Édipo - o sujeito que deseja a mãe tendo o pai como obstáculo, por isso mata-o e atinge seu objeto de desejo tornando-se rei de Tebas. O mito de Édipo está aqui representado pelo $\$$ e pelo $\Phi$, cetro do poder da realeza, do conhecimento, da busca da verdade. Édipo: o conquistador; Édipo: o falo; Édipo: o rei.

Mas, ao descobrir a verdade sobre seus crimes, Édipo fura os olhos e é exilado, passando, portanto, da posição de sujeito a objeto-dejeto, perdendo a coroa, o reino, o cetro e o poder. Assim, desfalicizado e cego, pergunta Lacan: será que ele se igualará a Tirésias, se tornando Outro e adquirindo o dom da adivinhação do manejo significante? Será ele efetivamente capaz de passar para o outro lado, o lado do não-todo?

É a essa metade do sujeito que atribui o mito de Tirésias.

\section{Tirésias, o cego vidente}

Tirésias é o personagem que, na peça de Sófocles, se apresenta como Mestre da Verdade, cego e adivinho, capaz de decifrar os enigmas e os agouros advindos dos deuses. É a ele que Édipo recorre para decifrar a origem da peste. Segundo a mitologia, quando jovem, ao passear no Monte Citéron, Tirésias cruzou com duas serpentes copulando. Ao bater nelas separando-as, ele se transforma em mulher. Sete anos depois, ao passar pelo mesmo local, encontra novamente cobras copulando e, ao fazer o mesmo, volta a ser homem. Devido a essa experiência insólita de ter conhecido os dois sexos, Tirésias foi chamado por Zeus e Hera para opinar sobre uma querela do casal. Quem goza mais no ato sexual: o homem ou a mulher? Tirésias disse que a mulher goza nove vezes mais do que o homem. Hera, ao ver assim desvelado o segredo feminino, ficou colérica e o fulminou com a cegueira. Zeus, para consolá-lo, deu-lhe a longevidade (para viver durante sete gerações) e o dom da adivinhação.

A característica, portanto, principal de Tirésias é a de conhecer o gozo feminino, esse gozo do Outro, para além do falo e da fala, obscuro e opaco, que as mulheres guardam no segredo do inefável - eis sua grande vidência. É esse gozo experimentado, para além da linguagem, que lhe permite ser Mestre da Verdade, que, como A mulher, é não-toda. O poder de adivinhação de ver para além das aparências é relativo ao enigma do gozo Outro.

O mito de Tirésias é um mito de um homem que experimentou o gozo feminino. Mito do trans - do para além do falo, do confim do gozo Outro que se enuncia pela lógica e se representa no mito de Tirésias que se fez, que se tornou o Outro. É esse o lugar ao qual Lacan, dando voz à Esfinge, nos conclama como o Édipo a advir. 
Diz a Esfinge em O aturdido: "Você me satisfaz, homenzinho... e depois de passar pelo meio dito do meio-dia você saberá na noite te fazeres igual a Tirésias, e como ele, por ter-se tornado Outro, adivinhar o que eu te disse" (Lacan, 1972/2003, p. 468).

Advir a esse lugar trans-fálico para poder manejar a mântica dos sonhos e o jogo da significância na interpretação analítica sobre o leito da ausência da relação sexual.

Tirésias, O-olhar-cego, enxerga para além das aparências, é portador de um olhar trans, olhar translúcido, do lado do não-todo, por ser reduzido ao objeto $a$ em sua função escópica. Tirésias também está no lugar de A mulher que não existe (LA F) e, por ter acesso a esse gozo, ele sabe do furo das mulheres e poros dos homens $[S(\mathbb{A})$ ]. Tirésias tem contato com o divino, O-que-transcende, e tem acesso ao gozo Outro, manipulando símbolos, lendo o voo dos pássaros, decifrando a atemporalidade do desejo no passado, presente e futuro.

O confronto entre Édipo e Tirésias, em Édipo rei, de Sófocles, é o embate do todo poderoso (fálico, rico, rei, conquistador, sondável, jovem) contra o velho cego (maltrapilho, sem eira nem beira) e que, no entanto, é dono de um saber misterioso e enigmático, que desvela o destino a Édipo - a quem o falo do poder impede de ter acesso à verdade não-toda e ao gozo trans-fálico da manipulação poética da linguagem (que é justamente aquilo que permite a Tirésias profetizar). É a esse lugar que é chamado o analista: conclamado a trans-passar a barreira do sexo e experimentar-se como semblante do objeto $a$.

\section{0 que os trans nos ensinam}

Letícia Lanz, trans-mulher de 67 anos, fez sua mudança de gênero de masculino para feminino aos 50 anos. É casada há quarenta anos com a mesma mulher, que acompanhou sua transição. Tem três filhos e quatro netos. Em palestra recente no Fórum Rio do Campo Lacaniano, afirmou que nunca quis ser mãe, mas sempre quis ser mulher, e que gosta mesmo é de mulher, diz ela, "em todos os sentidos". Por outro lado, afirmou que ao tornar-se mulher não deixou de ser pai e nem avô. Entre seus filhos, sua única filha foi a quem mais se incomodou e resistiu à sua transição. Até o momento em que, passando por um drama em sua vida, ela foi procurar Letícia e confessou seu temor de perder o pai que virou mulher. Letícia lhe disse: "Minha filha, eu jamais deixei de ser seu pai." E ela desabou em seus braços chorando e pedindo colo.

Outro dia foi com o neto ao supermercado. Na fila da caixa, ele se vira para Letícia e diz: "Oh vô, pode me comprar uma bala?" A moça do caixa corrige: "Não é avô, e sim avó!” O menino se vira para Letícia e comenta: "Ela é boba, né, vô?"

Os trans demonstram o que a psicanálise ensina: a mãe não coincide com a mulher, e a função paterna está disjunta da posição masculina. Nossa era trans é lacaniana, a exemplo da homoparentalidade, que denuncia que o Édipo está para além da pequena família burguesa. Ela não se constitui por papai e mamãe, mas 
pelo Nome-do-Pai e pelo Desejo da Mãe, significantes a serem sustentados por quem quer que seja, independente do sexo, do gênero e da posição sexuada. Os transgêneros, por sua vez, só demonstram o que aprendemos com Lacan: a posição sexuada está para além da anatomia. E que o lugar a ser preferencialmente ocupado na partilha dos seres - fálico ou não-todo - pode inspirar os semblantes de gênero que são escolhidos, esculpidos e inventados.

Em O aturdito, Lacan propõe partir de dois universais, dois todos suficientemente consistentes para separar nos seres falantes duas metades: metade homem e metade mulher, ressaltando que a identificação a cada uma dessas metades é um assunto em que o Eu domina, ou seja, o Eu corporal, o imaginário. Mas ao situar o falo como função, não se trata mais de um assunto do Eu, não é mais da ordem imaginária. Quando falamos, portanto, de dois universais - HOMEM, MULHER - trata-se da identificação imaginária e esses dois lados constituídos pelos dois significantes; estamos aí no nível do binarismo tão criticado pela teoria queer.

A psicanálise não é uma psicologia do ego, nem o âmbito da identificação imaginária. A psicanálise trata do sujeito que se inscreve ou não na função fálica e que vai responder a ela pelo modo com o qual constitui um argumento. A inscrição na função fálica significa que o sujeito tem relação com o sexo - cada um a seu modo. Essa relação singular ao sexo é seu modo particular de suprir a relação sexual que não se escreve.

Lacan chama os dois lados da fórmula da sexuação de metades do sujeito.

Podemos ter duas leituras dessas duas metades: 1. há sujeito que se identifica com uma metade, e outros sujeitos, com a outra metade - de um lado está "o sujeito que se propõe ser dito" homem, e do outro lado, o "sujeito que se propõe ser dito" mulher - segundo a expressão de Lacan em $O$ aturdito; 2. outra leitura é que se trata de duas metades de um sujeito que pode circular por ambos os lados e pelas quatro posições de gozo.

\section{Primeira leitura}

$\mathrm{Na}$ primeira leitura, trata-se da divisão do que impropriamente se chama de "humanidade reportada em identificações sexuais" (Lacan, 1975, p. 74). Lacan chama essa divisão de "tomagem" - como uma homenagem ao tomòs, corte em grego. Ironicamente ou não, temos aí comparecendo um corte que separa os seres falantes. A distribuição deles em dois campos distintos se dá a partir do corte da diferença sexual que não cessa de se escrever, pois ela se sustenta na relação sexual que não cessa de não se escrever. São esses lugares que dão, segundo Lacan, sentido aos semblantes de homem ou de mulher. Cada um pode se inscrever de um lado ou do outro assumindo o "status de mulher ou de homem". ${ }^{1}$ Há uma identifi-

1 A expressão "assumir o status de mulher ou homem" é uma expressão de Lacan. Ao se referir ao lado não-todo fálico, ele diz tratar-se do "campo de todos os seres que assumem o status da mulher" (Lacan, 1975, p. 75). 
cação e uma modalidade própria de gozo aos falasseres, que estão do lado do todo fálico, e outras para os que estão do lado do não-todo fálico. São os que se dizem homens e os que se dizem mulher. Ressaltamos aqui que não há nada da ordem de ser homem ou mulher, nem do parecer, que se refere aos semblantes de Homem e de Mulher, que são identificações simbólicas aos significantes Homem e Mulher, com seus significados próprios a cada cultura, que cada sujeito vai incorporar de modo singular e próprio. O que está em jogo são duas posições assumidas preferencialmente denominadas, não homem e mulher, e sim todo fálico e não-todo fálico, sustentadas pela não relação sexual. O gozo fálico e o objeto $a$ mais-de-gozar vêm suprir essa não relação. As duas posições sexuadas não constituem dois todos, dois universais, pois do lado do não-todo, é um "todo fora do Universo", como diz Lacan (O aturdito). Não há, portanto, binarismo algum, pois de um lado temos o Um, e do outro lado o "não tem nada"; de um lado um conjunto universal e do outro um conjunto aberto; de um lado o instituído e do outro lado o diferente, o estranho, o sempre Outro. Assim, a diferença sexual relida a partir das fórmulas da sexuação é a diferença entre gozos, entre as posições e entre os argumentos que fazem alguém dizer-se do lado do todo fálico e o não-todo fálico, do lado do pelotão ou fora dele. Trata-se da diferença radical entre o Um e o Outro. Essa diferença, que é sexual, tem um nome: heteridade. E a relação ao sexo é a modalidade do argumento com a qual responde cada sujeito à função fálica.

Tanto macho quanto fêmea podem aí inscrever seu argumento, tanto de um lado quanto do outro. Como diz Lacan: "o interessante é haver mulheres que não desdenham entrar no pelotão” (1972/2003, p. 468).

\section{Segunda leitura}

Uma segunda leitura possível é considerar as fórmulas da sexuação como as diferentes posições que um mesmo sujeito pode tomar em relação à vida sexual. E isto independente de seu sexo, gênero ou de orientação sexual. Essa leitura implica a plasticidade sexual, a circulação do sujeito por todas as posições: sujeito, objeto, falo e A mulher que não existe. Do lado do todo fálico, ele pode ocupar a posição de sujeito desejante e de falo, isto é, reduzir o parceiro ou parceira sexual para gozar dele ou dela como objeto, ou sustentar o falo cujo brilho atrai o parceiro ou parceira do Outro sexo, seja ele macho ou fêmea, que está no lugar da mulher que não existe. Não há dúvida de que fêmeas humanas XX são sujeitos desejantes e podem ser tão fálicas que atraem - por isso mesmo - seus parceiros e suas parceiras sexuais. “A mulher tem relação com o $\Phi$ ” (Lacan, 1975, p. 75) — é o significante que suporta no homem (aqui se trata do macho) o gozo fálico. Nem por isso deixam de circular pelas posições de objeto $a$ e de A mulher que não existe. O macho humano XY também pode se situar como objeto causa de desejo além de sujeito e ocupar o lugar de A mulher que não existe atraído pela posição 
fálica da parceira ou do parceiro. Essa posição da não-toda faz com que o sujeito aí se divida entre o falo (buscado no parceiro sexual) e sua solidão. Assim, o mesmo sujeito, independente do destino que sua anatomia impõe, pode se deslocar e trans-passar o outro lado indo para o não universo do não-todo fálico. Na vida sexual, essas posições são plásticas, tendo cada uma suas preferências e fixações na cama ou fora dela.

\section{Conclusão}

Em psicanálise falamos com Freud de escolha da neurose, referindo-se à escolha da estrutura clínica e, com Lacan, de escolha forçada, referindo-se à alienação significante. A partir dos últimos desenvolvimentos da teoria lacaniana, podemos também falar não só de escolha da orientação sexual homo ou hetero, mas também da escolha da posição sexuada e dos semblantes de gênero. Falar de escolha sempre implica a ética. Tratar as posições sexuadas como escolhas é abordar esse tema, tão central em nossa era trans, sem que qualquer uma dessas escolhas seja patologizada ou vinculada a alguma estrutura clínica, ou reduzida a um efeito do discurso capitalista, ou efeito dos avanços da ciência, ou ainda efeito de uma suposta epidemia de histeria coletiva.

Para concluir, essas duas metades do sujeito sexuado poderiam dar a impressão, ou a ilusão, de um suposto binarismo Homem-Mulher, encontrada na lógica predicativa que divide aqueles que têm o falo e os que não o tem. E mesmo "o apoio dos dois que esse não-todo parece nos apresentar", diz Lacan, "cria uma ilusão" (Lacan, 1972/2003, p. 468). Mas o que está do lado do não-todo é um inaccessível, diz ainda Lacan, é da ordem do trans - transfinito. Número transfinito é a forma rigorosa usada pela matemática para contar o número de elementos de conjuntos infinitos.

O analista, em sua análise, precisa ir para-além da posição de sujeito e da lógica fálica. É necessário ir para a "outra metade" que seria melhor chamar de a "metade outra", que é o dark side of the moon para além do falo. Lá onde correm os moon rivers.

A travessia da fantasia consiste em ir para o outro polo subjetivo que é o objeto $a$, aquilo que fundamentalmente nos determina. Essa travessia se conjuga à passagem do todo fálico ao não-todo fálico; à saída da lógica fálica, do universo totêmico, dito patriarcal, universo das identidades e identificações edipianas, para o não universo, o transfinito; à zona de lalíngua, da criação e da poesia.

O lugar do analista é o lugar do não-todo. O não lugar, como lugar do sem razão, da ausência de relação sexual, da desidentidade, do puro semblante de objeto $a$, o próprio lugar do para além, para além do UM, para além do TUDO, do todo e da toda. É propriamente o lugar TRANS - que é um prefixo utilizado em certas palavras para designar o para além, o au-delà, e através. 
Assim, a passagem a analista numa análise, além da travessia da fantasia, é uma trans-passagem, uma trans-formação, para além de qualquer formato ou formação. Lá onde se trans-borda, trans-cende, trans-creve. Trans-passagem possibilitada pelo amor, esse amor trans que é a trans-ferência. Deveríamos, portanto, trocar o nome de Formação do Analista para Trans-formação do Analista. E assim, poder cumprir nossa trans-missão da psicanálise.

\section{Referências bibliográficas}

Freud, S. (1920/1976). A psicogênese de um caso de homossexualidade feminina. (Jayme Salomão, Trad.). In S. Freud. Edição standard brasileira das obras psicológicas completas de Sigmund Freud (Vol. 18, pp. 91-109). Rio de Janeiro: Imago.

Freud, S. (1932/1976) A feminilidade. Novas Conferências Introdutórias XXXIII. (Jayme Salomão, Trad.). In S. Freud. Edição standard brasileira das obras psicológicas completas de Sigmund Freud (Vol. 22, pp. 113-134). Rio de Janeiro: Imago.

Lacan, J. (1972/2003). O aturdito. In J. Lacan. Outros escritos (pp. 448-497). (Vera Ribeiro, Trad.). Rio de Janeiro: Jorge Zahar.

Lacan, J. (1975). Le séminaire, livre XX: encore. Paris: Seuil.

Recebido: 02/11/2017

Aprovado: 30/11/2017 